\title{
Influence of ABCB1 C3435T gene polymorphisms on tumor response to neoadjuvant chemotherapy in locally advanced breast cancer patients from Northeastern Brazil.
}

\section{Diego de Aragão Bezerra}

Universidade Federal do Ceara - Campus Sobral

Jose Juvenal Linhares ( $\sim$ juvenallinhares@gmail.com )

Universidade Federal do Ceará https://orcid.org/0000-0003-1356-4182

Emmanuelle Coelho Noronha

Universidade Federal do Ceara - Campus Sobral

Kaio César Simiano Tavares

Universidade de Fortaleza

André Saraiva Leão Marcelo Antunes

Universidade de Fortaleza

Regina Freitas Coelho

Universidade de Fortaleza

Marcos Vinicius Souza Marques

Universidade Federal do Ceara - Campus Sobral

Research article

Keywords: Breast cancer, Neoadjuvant Chemotherapy, Polymorphisms, Gene ABCB1

Posted Date: October 29th, 2019

DOI: https://doi.org/10.21203/rs.2.16585/v1

License: (c) (1) This work is licensed under a Creative Commons Attribution 4.0 International License. Read Full License 


\section{Abstract}

Background: Breast cancer (BC) is the most common tumor and the leading cause of cancer-related death among the female population worldwide. To evaluate the association between the ABCB1 C3435T single gene nucleotide polymorphisms (SNPs) with the response to neoadjuvant chemotherapy in women with breast cancer.

Methods: This study included 32 female patients who received neoadjuvant chemotherapy. The polymorphisms were genotyped through real-time allele-specific polymerase chain reaction (PCR). The statistical analysis was performed using the Fisher's exact test or Pearson's chi-square test in the Statistical Package for Social Sciences (SPSS) version 20.0 software.

Results: The genotypes found for the C3435T polymorphism were in Hardy-Weinberg equilibrium and their genotypic distributions were $\mathrm{CC}=10(31.1 \%), \mathrm{CT}=14(43.8 \%)$, and $\mathrm{TT}=08(25.0 \%)$ with $\times 2$ : 0.86 and $\mathrm{p}$-value $>0.05$. Allele frequencies were $\mathrm{C}=0.54$ and $\mathrm{T}=0.46$. There were no significant statistical differences between genotypes considering the response to neoadjuvant chemotherapy and immunohistochemistry; the presence of the T allele was associated with worsen axillary status response to neoadjuvant chemotherapy.

Conclusion: No definite association between the presence of C3435T polymorphism and the response to neoadjuvant chemotherapy was observed. Further studies in Brazil involving larger samples will contribute to validating the results of this study. Keywords: Breast cancer; Neoadjuvant Chemotherapy; Polymorphisms; Gene ABCB1

\section{Background}

Breast cancer (BC) is the most common tumor and the leading cause of cancer-related death among the female population worldwide [1]. Locally advanced breast cancer $(L A B C)$ represents a heterogeneous group of diseases associated with poor prognoses. According to the TNM staging system from the International Union Against Cancer (UICC)/American Joint Cancer Committee (AJCC), primary $\mathrm{BC}$ with extension to the skin, chest wall or inflammatory carcinoma, with or without lymph node involvement, and without metastasis can be included in stage III and considered a LABC [2].

Several studies are being conducted on the pharmacogenomics of antineoplastic chemotherapy drugs to reduce the dose and minimize undesirable effects by individualizing treatment. Neoadjuvant chemotherapy (NAC) is one of the most widely used forms of treatment for its effectiveness in certain potentially lethal neoplasms such as those in the breast, especially in patients with LABC [3]. NAC is a systemic therapy given before surgery to minimize the extent of surgery, reducing tumor size, and facilitating a conservative breast approach [4]. Researches had shown a significant increase in pathological response in primary BC patients when docetaxel was administered as the sequential therapy to doxorubicin and cyclophosphamide in a neoadjuvant scenario [5]. Randomized studies showed similar NAC responses compared to adjuvant therapy, [6] encouraging the use of docetaxel in 
neoadjuvant settings. NAC followed by surgery, and adjuvant radiotherapy is the standard treatment for LABC patients. [7]. However, the frequency of tumor regression shows rates ranging from 10 to $50 \%$, and up to complete pathological response, however, NAC is ineffective in a large number of patients [8]. The reasons for this heterogeneity may be due to genetic and non-genetic factors [9].

Genetic factors may influence the therapeutic efficacy and interfere with the survival of patients with $B C$, even those at similar clinical stages. Therefore, the availability of new biomarkers that can more accurately predict prognosis and treatment response is a central issue for improving therapeutic strategies [10].

$A B C B 1$, the multi-drug resistance (MDR) gene, is responsible for reducing intracellular drug levels by the ATP-dependent efflux. The main factors leading to simultaneous resistance to various drugs are drug expulsion after entering the plasma membrane via efflux pumps, reduced uptake, altered target enzymes, altered drug metabolism, increased DNA repair, or failure of regulatory mechanisms of programmed cell death (apoptosis). One of these mechanisms is through host efflux pumps, and among them, the Pglycoprotein (P-gp), $[10,11]$ which is involved in the chemotherapy drug resistance presented by tumor cells [12]. Because the current knowledge in this field is inconsistent and sometimes conflicting, further studies are needed to confirm the clinical importance of single gene nucleotide polymorphisms (SNPs) encoding these multidrug resistance enzymes [13].

This is the first study carried out with the primary objective of evaluating the association between the ABCB1 rs1045642 (C3435T) gene polymorphism and the response to NAC in patients with BC in Northeastern Brazil. This study consisted to evaluate the association between the ABCB1 C3435T SNPs and the response to NAC in women with $\mathrm{BC}$.

\section{Results}

The demographic characteristics, risk factors, and tumor characteristics of women with BC are described in Table 1.

Table 1: Demographic characteristics of the study population $(N=32)$. 


\begin{tabular}{|c|c|c|}
\hline Epidemiological data & $\mathbf{n}$ & $\%$ \\
\hline \multicolumn{3}{|l|}{ Age (51.56 \pm 11.15$)$} \\
\hline Up to 50 years old & 16 & 50.0 \\
\hline Over 50 years old & 16 & 50.0 \\
\hline \multicolumn{3}{|l|}{ Family history } \\
\hline No & 20 & 62.5 \\
\hline Yes & 12 & 37.5 \\
\hline \multicolumn{3}{|l|}{ Smoking } \\
\hline No & 25 & 78.1 \\
\hline Yes & 7 & 21.9 \\
\hline \multicolumn{3}{|l|}{ Menarche Age (13.23 \pm 2.18$)$} \\
\hline Up to 12 years old & 11 & 36.7 \\
\hline Over 12 years old & 19 & 63.3 \\
\hline \multicolumn{3}{|l|}{ Menopause Age $(44.30 \pm 6.26)$} \\
\hline Up to 45 years old & 13 & 48.1 \\
\hline Over 45 years old & 14 & 51.9 \\
\hline \multicolumn{3}{|c|}{ First childbirth age $(20.61 \pm 5.75)$} \\
\hline Up to 20 years old & 12 & 52.2 \\
\hline Between 21 and 30 years old & 9 & 39.1 \\
\hline Over 30 years old & 2 & 8.7 \\
\hline \multicolumn{3}{|l|}{ Pregnancies $(3.16 \pm 1.49)$} \\
\hline 1 & 4 & 16.0 \\
\hline 2 to 3 & 11 & 44.0 \\
\hline$>3$ & 10 & \\
\hline \multicolumn{3}{|l|}{ Hormone receptors } \\
\hline Negative & 5 & 15.6 \\
\hline Positive & 27 & 84.4 \\
\hline \multicolumn{3}{|l|}{ HER2 } \\
\hline Negative & 12 & 44.4 \\
\hline
\end{tabular}


$\begin{array}{lll}\text { Positive } & 10 \quad 62.5\end{array}$

ki67 (31.07 \pm 26.26$)$

$<15 \%$

$>15 \% \quad 22 \quad 68.8$

Response to NAC

$\begin{array}{lcc}\text { Partial } & 28 & 87.5 \\ \text { Complete } & 4 & 12.5\end{array}$

Data are expressed in average \pm SD

The genotypic distribution showed 10 (31.2\%) as homozygous (CC), 08 (25\%) as homozygous (TT), and $14(43.8 \%)$ as heterozygous (CT).

No association between the presence of the $C$ allele and response to NAC was observed, nor its association with the lymph node status, hormone receptors, HER-2, and KI-67 (Table 2).

Table 2: Association between the ABCB1 rs1045642 (C3435T) SNP genotype and the NAC response (C/T + CC vs. TT). 


\section{Genotype}

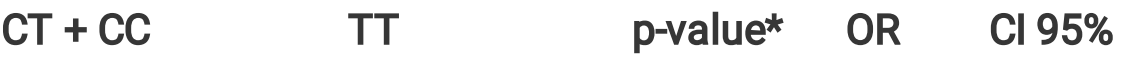

\section{NAC Response}

$\begin{array}{lllllllll}\text { Partial } & 21 & 87.5 \% & 7 & 87.5 \% & 1.000 & 1.00 & 0.09 & 11.24 \\ \text { Complete } & 3 & 12.5 \% & 1 & 12.5 \% & & 1 & & \end{array}$

Post NAC lymph node response

\begin{tabular}{lllllllll} 
Negative & 7 & $29.2 \%$ & 4 & $50.0 \%$ & 0.397 & 0.41 & 0.08 & 2.13 \\
\hline Positive & 17 & $70.8 \%$ & 4 & $50.0 \%$ & & 1 & &
\end{tabular}

Hormone receptors

$\begin{array}{lllllllll}\text { Negative } & 5 & 20.8 \% & 0 & 0 \% & 0.296 & 4.80 & 0.24 & 96.87 \\ \text { Positive } & 19 & 79,2 \% & 8 & 100.0 \% & & 1 & & \end{array}$

HER2

$\begin{array}{lllllllll}\text { Negative } & 11 & 45.8 \% & 1 & 12.5 \% & 0.204 & 5,92 & 0.63 & 55.88 \\ \text { Positive } & 13 & 54.2 \% & 7 & 87.5 \% & & 1 & & \end{array}$

ki 67

$\begin{array}{lllllllll}<15 & 8 & 33.3 \% & 2 & 25.0 \% & 1.000 & 1.50 & 0.25 & 9.18 \\ >15 & 16 & 66.7 \% & 6 & 75 \% & & 1 & & \end{array}$

${ }^{*} \mathrm{p} \leq 0.05$ was considered significant.

Table 3 shows that, when assessing the association of the T allele with the NAC response, a significant difference was observed about the lymph node status after NAC, however, without association with tumor size reduction or immunohistochemical markers.

Table 3: Association between the ABCB1 rs 1045642 (C3435T) SNP genotype and the NAC response (CT + TT vs. CC). 


\section{Genotype}

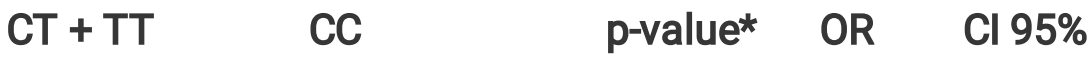

NAC Response

\begin{tabular}{lllllllll} 
Partial & 20 & $90.9 \%$ & 8 & $80.0 \%$ & 0.387 & 2.50 & 0.30 & 20.92 \\
\hline Complete & 2 & $9.1 \%$ & 2 & $20.0 \%$ & & 1 & &
\end{tabular}

Post NAC lymph node response

$\begin{array}{lllllllll}\text { Negative } & 10^{*} & 45.5 \% & 1 & 10.0 \% & \mathbf{0 . 0 4 8} & \mathbf{7 . 5 0} & \mathbf{1 . 1 1} & \mathbf{6 9 . 7 4} \\ \text { Positive } & 12 & 54.5 \% & 9 \text { th } & 90.0 \% & & 1 & & \end{array}$

\section{Hormone receptors}

$\begin{array}{lllllllll}\text { Negative } & 2 & 9.1 \% & 3 & 30.0 \% & 0.293 & 0.23 & 0.03 & 1.70 \\ \text { Positive } & 20 & 90.9 \% & 7 & 70.0 \% & & 1 & & \end{array}$

\section{HER2}

$\begin{array}{lcccccccc}\text { Negative } & 8 & 36.4 \% & 4 & 40.0 \% & 1.000 & 0.86 & 0.18 & 3.98 \\ \text { Positive } & 14 & 63.6 \% & 6 & 60.0 \% & & 1 & & \\ \text { ki } 67 & & & & & & & & \\ <15 & 7 & 31.8 \% & 3 & 30.0 \% & 1.000 & 1.09 & 0.21 & 5.52 \\ >15 & 15 & 68.2 \% & 7 & 70.0 \% & & 1 & & \end{array}$

${ }^{*} \mathrm{p} \leq 0.05$ was considered significant.

No statistical difference was observed in any of the studied variables when the association between the wild homozygote (CC) and the mutated (TT) genotype was evaluated (Table 4).

Table 4: Association of the ABCB1 rs1045642 (C3435T) SNP genotype with the NAC response (CC vs. TT). 


\section{Genotype}

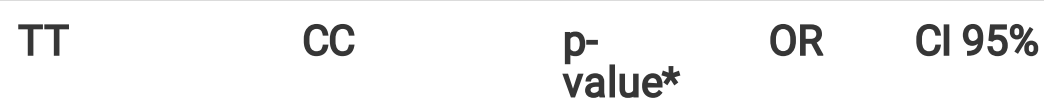

\section{NACT Response}

$\begin{array}{lllllllll}\text { Partial } & 7 & 87.5 \% & 8 & 80.0 \% & 1.000 & 1.75 & 0.13 & 23.70 \\ \text { Complete } & 1 & 12.5 \% & 2 & 20.0 \% & & 1 & & \end{array}$

Post NAC lymph node response

$\begin{array}{lllllllll}\text { Negative } & 4 & 50.0 \% & 1 & 10.0 \% & 0.118 & 9.00 & 0.75 & 108.31 \\ \text { Positive } & 4 & 50.0 \% & 9 & 90.0 \% & & 1 & & \end{array}$

\section{Hormone \\ receptors}

$\begin{array}{lllllllll}\text { Negative } & 0 & , 0 \% & 3 & 30.0 \% & 0,216 & 0.13 & 0.01 & 2861.00 \\ \text { Positive } & 8 & 100.0 \% & 7 & 70.0 \% & & 1 & & \end{array}$

\section{HER2}

$\begin{array}{lllllllll}\text { Negative } & 1 & 12.5 \% & 4 & 40.0 \% & 314 & 0.21 & 0.02 & 2.48 \\ \text { Positive } & 7 & 87.5 \% & 6 & 60.0 \% & & & & \end{array}$

\section{ki 67}

$\begin{array}{lllllllll}<15 & 2 & 25.0 \% & 3 & 30.0 \% & 1.000 & 0.78 & 0.10 & 6.32 \\ >15 & 6 & 75 \% & 7 & 70.0 \% & & 1 & & \end{array}$

${ }^{*} \mathrm{p} \leq 0.05$ was considered significant.

\section{Discussion}

This study aimed to evaluate the association between the SNP polymorphism of the ABCB1-C3435T gene and the clinical response to NAC in women with breast cancer in northeastern Brazil.

We evaluated the action of this genetic polymorphism related to the multidrug resistance mechanism, where a complex phenomenon is observed, and contradictory results can be explained by gene-gene interactions. TT genotypes are involved in a defect in the p-glycoprotein production, which leads to drug accumulation within cells. However, other mechanisms may occur, resulting in resistance to chemotherapy. Other unknown polymorphisms in the MDR-1 gene and errors in the translation of the pglycoprotein structural protein that may render it defective are observed in patients with the CC genotype. [15]. We evaluated 32 patients with genotypes distributed as CC (31.2\%), TC (43.8\%), and TT (25\%). 
These results are in agreement with those reported by Priyadarshini et al. in the southern Indian population with $B C(n=102)[15]$. In a meta-analysis study, nine of the articles included studies on the ABCB1-C3435T gene polymorphism (770 patients), where the most prevalent genotype was CT [16]; however, there were no South American studies in that analysis. Rodrigues et al. studied BC patients from southeastern Brazil and found distribution patterns similar to our results with $27.9 \%$ for $\mathrm{CC}, 52.2 \%$ for $\mathrm{CT}$, and $20.3 \%$ for TT [17].

The association of the ABCB1-C3435T polymorphism and response in patients with BC treated with NAC was initially suggested in a study with $68 \mathrm{LABC}$ patients where those who presented better clinical responses were TT genotype carriers (OR: 4.38, 95\% Cl: 1.2-16.1, p = 0.029) [18]. In a meta-analysis study, nine articles involving the ABCB1-C3435T gene polymorphism (770 patients) indicated that the polymorphism was not associated with the NAC response in BC patients [16,18]. These results are similar to those in our study where we found no association between the SNP C3435T polymorphism of the MDR-1 gene and tumor response to NAC, hormone receptors, and HER-2 and Ki-67 expression.

This study showed that the presence of the T allele was related to worse axillary status. The last study that mainly assessed axillary status was conducted in Brazil and showed discordant findings, i.e., no relationship between axillary involvement and the relationship between alleles [17]; this discordance may be justified by the difference in sample and country region where the studies were conducted.

The present study is extremely important in the attempt to search for markers involved with the NAC response in women with $B C$, which could modify the treatment approach adopted for women with $B C$, especially within the Northeastern region of Brazil.

\section{Conclusions}

The study shows that there was no statistical difference between the presence of C3435T polymorphism genotypes regarding the response to NAC; nevertheless, a worse response of axillary status was observed in the presence of the T allele. Further studies in Brazil involving larger samples will contribute to validating the results of this study.

\section{Methods}

\section{Study Design}

This was an observational and prospective study in women with histopathological diagnosis of $\mathrm{BC}$ at clinical stage III, without previous treatment, and submitted to NAC. These patients were assisted at the Mastology Service of the Teaching Hospital of the Federal University of Ceará-Campus Sobral - Santa Casa de Misericórdia of Sobral and Ambulatory of the Center of Medical Specialties (CEM) of the Health Secretary of the city of Sobral - CE.

\section{Sampling}


DNA samples were extracted from 32 consecutive patients with LABC (clinical stage III). The cases were assessed between July of 2017 and July of 2018; patients were evaluated by physical examination and mammography, and the stage was confirmed histopathologically in thick needle biopsies. All patients completed platinum and docetaxel-based NAC, surgery, radiotherapy, and hormone therapy when indicated. The response to chemotherapy was performed by the pathological analysis of the surgical specimen and clinically and radiologically after the last NAC cycle. Tumor response was assessed according to the RECIST criteria (Response Evaluation Criteria in Solid Tumor) [14], using reports from physical examination and mammographic images performed before the beginning of the first cycle and after the completion of all docetaxel cycles, and the histopathological report from the surgical specimen. According to the RECIST criteria, [14] the complete response (CR) represented the disappearance of all lesions assessed by the histopathological examination of the surgical specimen; the partial response (PR) represented $\geq 30 \%$ reduction in the sum of the largest diameters compared with those in the first examination (baseline); and progressive disease (PD) represented an increase in $\geq 20 \%$ in the sum of the largest diameters compared to the smallest sum recorded (not necessarily the baseline). The stable disease (SD) status does not fit into progression or response [14].

The exclusion criteria were intolerance to NAC, which prevented the completion of treatment, pregnancy, male gender, and metastatic or bilateral disease.

The study was approved by the Research Ethics Committee of the Federal University of Ceará (CAAE number: 78756016.5.0000.5054 and Opinion Number: 2,348,336). The informed consent form was signed, allowing the use of tissue samples in molecular analyses by all study participants prior to the study start.

\section{Genetic Analysis}

\section{DNA Extraction}

DNA was extracted by scraping the oral mucosa with a cytobrush according to the GFX ${ }^{\circledR}$ Cell, Tissue, and Blood Kit protocol (Amersham-Pharmacia ${ }^{\circledR}$ ). DNA samples were used to perform the PCR real time to obtain the $249 \mathrm{bp}$ fraction that includes the C3435T polymorphic region located on exon 26; the 5'-ATG GCC TCC GAG CAC sense primers and ACC TG-3 'and 5'-AGG CAG TGA CTC GAT GAA GGC-3' antisense primers were used (Invitrogen ${ }^{\text {TM }}$ Life Technologies, Carlsbad, $C A \AA$ ) in an Eppendorf PCR thermocycler (Eppendorf GAC 22331, Hamburg, Germany ${ }^{\circledR}$ ). The functional variants of the ABCB1 gene (c.3435C> T / rs1045642) were the CC genotype considered as a reference for comparisons with the CT (heterozygote) and TT (homozygote) variants. Genotyping was performed using the TaqMan $\circledast$ SNP assay (Applied Biosystems ${ }^{\circledR}$, ID: C_7586657_20). Between 1 and 20 ng of DNA was used in PCR reactions performed in triplicates at the final volume of $20 \mathrm{ml}$ using the $A B I 7500$ real-time PCR detection system (Applied Biosystems $\left.{ }^{\circledR}\right)$. The cycling conditions were $50^{\circ} \mathrm{C}$ for $2 \mathrm{~min}, 95^{\circ} \mathrm{C}$ for $10 \mathrm{~min} ; 40$ cycles at $92^{\circ} \mathrm{C}$ for $15 \mathrm{~s}$; and pairing/extension at $60^{\circ} \mathrm{C}$ for $1 \mathrm{~min}$. Data were analyzed using the SDS v. 1.3.1® software.

\section{Statistical Analysis}

Page $10 / 13$ 
Data were expressed as mean and standard deviation after categorization as absolute and percentage frequency and analyzed by the Fisher's exact test or Pearson's chi-square test.

The Fisher's exact or Chi-square association tests were used to evaluate the relationship of the tested genotypes (C3435T polymorphism genotypes) and the response to the neoadjuvant chemotherapy, and the lymph node response after therapy.

Analyzes were performed using the Statistical Package for the Social Sciences (SPSS)Ò software, version 20.0 for Windows, adopting a $95 \%$ confidence and $p$-value $\leq 0.05$ as significant.

\section{Abbreviations}

BC: Breast cancer, LABC: Locally advanced breast cancer, UICC: International Union Against Cancer, AJCC: American Joint Cancer Committee, NAC: Neoadjuvant chemotherapy, MDR: multi-drug resistance, P-gp: Pglycoprotein, SNPs: single gene nucleotide polymorphisms, CEM: Center of Medical Specialties, RECIST: Response Evaluation Criteria in Solid Tumor, SD: stable disease, CR: complete response, PR: partial response, PD: progressive disease, PCR: polymerase chain reaction, SPSS: Statistical Package for Social Sciences.

\section{Declarations}

\section{Acknowledgments}

The authors are thankful to the Graduate Program Coordinator of the University of Fortaleza, Dra. Adriana Rolim, and the Center for Experimental Biology, Laboratory of Molecular and Developmental Biology.

\section{Author's contributions}

DAB and JJL designed this study. ECN, KCST, ASLMA, RFC and MVSM carried out all the experiments, sampling and data analysis. JJL supervised the whole processes in this study. DAB and JJL wrote the manuscript. All authors read and approved the final manuscript.

\section{Funding}

The research was funded through resources from the Research Support Notice of the Department of Teaching and Research (DEPE) - Notice from 06/2016 from the Teaching Hospital of the Federal University of Ceará-Campus Sobral - Santa Casa de Misericórdia of Sobral.

\section{Ethics approval and consent to participate}

The study was approved by the Research Ethics Committee of the Federal University of Ceará (CAAE number: 78756016.5.0000.5054 and Opinion Number: 2,348,336). The informed consent form was 
signed, allowing the use of tissue samples in molecular analyses by all study participants prior to the study start.

\section{Availability of data and materials}

Not applicable.

\section{Consent for publication}

Not applicable.

\section{Competing interests}

The authors declare that they have no conflict of interests.

\section{Author details}

${ }^{1}$ Postgraduate in Health Sciences of the Federal University of Ceará - Campus of Sobral, ${ }^{2}$ Department of Obstetrics and Gynecology of the Federal University of Ceará - Campus of Sobral, ${ }^{3}$ Gynecology Service of the Hospital Santa Casa of Misericordia of Sobral, ${ }^{4}$ Laboratory of Molecular Biology and Development, University of Fortaleza.

\section{References}

1. Bray, F, Ferlay, J, Soerjomataram, I, Siegel, RL, Torre, LA, Jemal, A. Global cancer statistics 2018: GLOBOCAN estimates of incidence and mortality worldwide for 36 cancers in 185 countries. CA Cancer J Clin. 2018; 68:394-424.

2. Singletary SE, Allred C, Ashley P, Bassett LW, Berry D, Bland KI, Borgen PI, Clark G, Edge SB, Hayes DF, Hughes LL, Hutter RV, Morrow M, Page D, Recht A, Theriault RL, Thor A, Weaver DL, Wieand HS, Greene FL. Revision of the American Joint Committee on Cancer staging system for breast cancer. J Clin Oncol. 2002, 20:3628-36. 区

3. Ciccolini J, Fanciullino R, Serdjebi C, Milano G. Pharmacogenetics and breast cancer management: current status and perspectives. Expert Opin Drug Metab Toxicol. 2015; 11:719- $》$

4. Akhtar M, Akulwar V, Kulkarni A, Bansal A. Role of neo-adjuvant chemotherapy in locally advanced breast cancer. Indian J Cancer. 2015; 52:286- $\bigotimes$

5. Rastogi P, Anderson SJ, Bear HD, et al. Preoperative chemotherapy: updates of National Surgical Adjuvant Breast and Bowel Project Protocols B-18 and B- J Clin Oncol. 2008; 26:778-85. 『

6. Asselain B, Barlow W, Bartlett $\mathrm{J}$, et al. Long-term outcomes for neoadjuvant versus adjuvant chemotherapy in early breast cancer: meta-analysis of individual patient data from ten randomised trials. Lancet Oncol. 2018; 19:27-

7. NCCN Clinical Practice Guidelines in Oncology [Internet];2017. https://www.nccn.org/professionals/physician_gls/f_guidelines. 
8. Kaufmann M, von Minckwitz G, Mamounas EP, Cameron D, Carey LA, Cristofanilli M, Denkert C, Eiermann W, Gnant M, Harris JR. Recommendations from an international consensus conference on the current status and future of neo-adjuvant systemic therapy in primary breast cancer. Ann Surg Oncol. 2012;19(5):1508-16

9. Noguchi S. Predictive factors for response to docetaxel in human $₫$ breast cancers. Cancer Sci. 2006; 97:813- $₫$

10. Taxane pathway [Internet]; 2016. https://www.pharmgkb.org/pathway/PA154426155. Accessed March 10,2019. $\otimes$

11. Jabir RS, Naidu R, Annuar MA, Ho GF, Munisamy M, Stanslas $\otimes$ Pharmacogenetics of taxanes: impact of gene polymor- phisms of drug transporters on pharmacokinetics and toxicity.

Pharmacogenomics. 2012; 13:1979-88. 『

12. Fletcher $\mathrm{JI}$, Haber M, Henderson MJ, Norris MD. ABC transporters in cancer: more than just drug efflux pumps. Nat Rev Cancer. 2010; 10(2):147-56

13. Mittal B, Tulsyan S, Mittal R. The effect of $A B C B 1$ polymorphisms on the outcome of breast cancer treatment. Pharmacogenomics Pers Med. 2016; 9:47- $\mathbb{Q}$

14. Eisenhauer EA, Therasse P, Bogaerts J, et al. New response evalua- tion criteria in solid tumours: revised RECIST guideline (version1.1). Eur J Cancer Oxf Engl. 2009; 45:228-

15. Priyadarshini R, Raj GM, Kayal S, Ramesh A, Shewade DG. Influence of ABCB1 C3435T and C1236T gene polymorphisms on tumour response to docetaxel-based neo-adjuvant chemotherapy in locally advanced breast cancer patients of South India. J Clin Pharm Ther. 2019; 44:188-96.

16. Madrid-Paredes A, Cañadas-Garre M, Sánchez-Pozo A, Expósito- Ruiz M, Calleja Hernández MÁ. ABCB1 gene polymorphisms and response to chemotherapy in breast cancer patients: a meta- Surg Oncol. 2017; 26:473-82.

17. Rodrigues FF, Santos RE, Melo MB et al (2008) Correlation of polymorphism C3435T of the MDR-1 gene and the response of primary chemotherapy in women with locally advanced breast cancer. Genet Mol Res 7:177-83

18. Kafka, G. Sauer, C. Jaeger, R. Grundmann, R. Kreienberg, R. Zeillinger, et al., Polymorphism C3435T of the MDR-1 gene predicts response to preoperative chemotherapy in locally advanced breast cancer, Int. J. Oncol. 2003; 22:1117-21. 区 